\title{
The Effect of Iron Tailing Powder on the Cement Mortar Strength
}

\author{
Yun-Fen $\mathrm{HOU}^{1, \mathrm{a}}$, Si-Ru ZHAO ${ }^{1, \mathrm{~b}}$, Wu-Bao $\mathrm{SI}^{1, \mathrm{c}}$ \\ ${ }^{1}$ Beijing High Institution Research Center for Engineering Structures and New Materials, Beijing \\ University of Civil Engineering and Architecture, Beijing, China \\ ahouyunfen@163.com, bxgbd_4069@163.com, csiwubao2014@qq.com
}

Keywords: Iron tailing Powder, Specific Strength, Contribution Rate of Activity, Fineness.

\begin{abstract}
The iron tailing powder can increases fluidity of cement mortar because the fluidity ratio of iron tailing powder whose fineness is $340 \mathrm{~m}^{2} / \mathrm{kg}$ is $105 \%$, and the fluidity ratio of grinded iron tailing powder whose fineness is $680 \mathrm{~m}^{2} / \mathrm{kg}$ is $120 \%$. The strengths increase with increasing of iron tailing powder dosage, but when dosage exceeds $10 \%$ strength decreases; for grinded iron tailing powder, when dosage does not exceed $30 \%$, strength increases; when dosage is same, grinded iron tailing powder can increase strength more than iron tailing powder. When dosage of iron tailing powder is less than $20 \%$, it can improve crack resistance. When dosage of iron tailing powder is less than $20 \%$ and grinded iron tailing powder is less than $50 \%$, specific strength and specific strength coefficient for 28 days are increased, and contribution rate of activity is greater than zero, which means that iron tailing powders benefit to strength.
\end{abstract}

\section{Introduction}

Iron tailing is waste discharged by iron work after selecting useful component from iron ore. According to statistics, iron works discharge iron tailing about 3 hundred million tons per annum in China, but the rate of multipurpose utilization of iron tailing is less than $20 \%$, such as mine fill, producing cement, new-type wall material and concrete aggregates, etc[1-7]. Because of the lack of iron ore, in order to improve efficiency of beneficiation, a lot of iron works grind iron ore much finer, which cause iron tailing powder finer and finer near to the fineness of cement. At same time, with the development of HPC, more and more the low active mineral admixtures are needed. The study about chemical composition, mineral composition, and microstructure and fluidity ratio of iron tailing powder shows that iron tailing powder has the performance of low active mineral admixture, in order to determine the impact extent of iron tailing powder on concrete, this paper researches the effect of iron tailing powder added with $0 \%$ to $50 \%$ on cement mortar fluidity and strength.

\section{Raw Materials and Experimental Method}

\section{Raw Materials}

The chemical compositions of iron tailing powder are shown in Tab.1, the mineral compositions are shown in Tab.2, and the microstructure is shown in Fig.1.

Tab.1 Chemical compositions of iron tailing powder

\begin{tabular}{c|c|c|c|c|c|c|c|c|c}
\hline $\mathrm{SiO}_{2}$ & $\mathrm{Al}_{2} \mathrm{O}_{3}$ & $\mathrm{FeO}_{3}$ & $\mathrm{CaO}$ & $\mathrm{MgO}$ & $\mathrm{K}_{2} \mathrm{O}$ & $\mathrm{Na}_{2} \mathrm{O}$ & $\mathrm{TiO}_{2}$ & $\mathrm{SO}_{3}$ & L.O.I \\
\hline 67.29 & 8.49 & 8.95 & 3.63 & 4.8 & 2.46 & 1.28 & 0.32 & 0.45 & 2.39 \\
\hline
\end{tabular}

Tab.2 Mineral compositions of iron tailing powder

\begin{tabular}{c|c|c|c|c|c|c|c|c}
\hline chlorite & quartz & feldspar & mica & hornblende & hematite & magnetite & calcite & dolomite \\
\hline 25.6 & 24.9 & 18.5 & 12.7 & 5.6 & 5.5 & 2.8 & 2.2 & 2.2 \\
\hline
\end{tabular}


It can be seen from Tab.1 and Tab.2 that the main chemical compositions of iron tailing powder is $\mathrm{SiO}_{2}$, about $67.29 \%$, and the mineral compositions are quartz, chlorite and feldspar crystals, etc. Fig. 1 shows that particle shape of iron tailing powder is irregular, and particles gather together, and after grinding, particles is much finer.

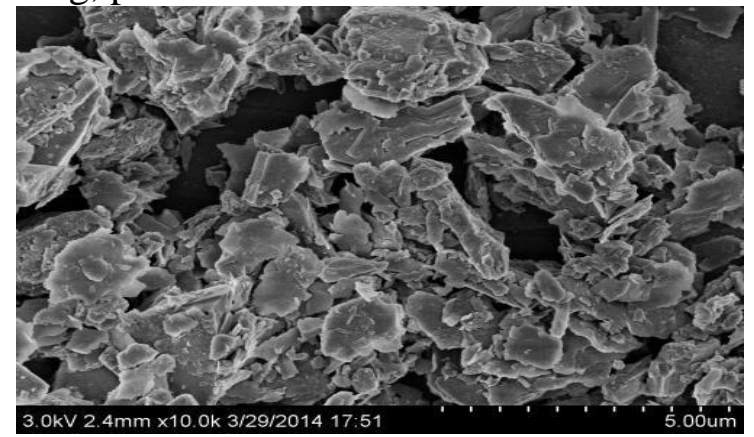

(a) original powder

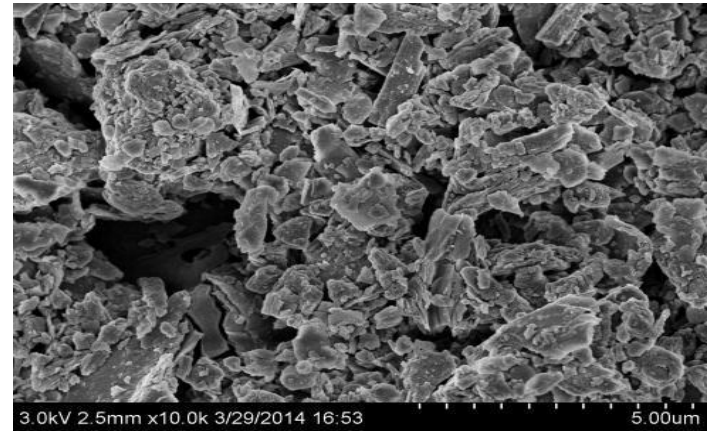

(b) grinded powder

Fig.1. microstructure of iron tailing powder

In generally, the more crystal microstructure defects and lattice distortion have in crystalline, the higher chemical activity is. When grinding iron tailing powder, mechanical force not only causes the particle size to decrease, but also cause more deformation of crystal structure. The specific surface area of original iron tailing powder (for short OP) is $340 \mathrm{~m}^{2} / \mathrm{kg}$, and is $680 \mathrm{~m}^{2} / \mathrm{kg}$ for grinded iron tailing powder (for short GP). The fluidity ratio of OP is $105 \%$, and is $120 \%$ for GP.

\section{The Ratio}

The standard ratio is cement: standard sand: water=1: $3: 0.5$, and two kinds iron tailing powders will substitute cement according to the mass ratio of 3\%, 5\%, $8 \%, 10 \%, 20 \%, 30 \%, 40 \%$ and $50 \%$ to prepare mortar specimens for studying the effect of iron tailing powder on fluidity and strength.

\section{Experimental Method}

The standard GB/2419-2005 is used to measure fluidity, and standard GB/T17671-1999 to measure flexural strength and compressive strength.

\section{Results and Analysis}

\section{Effect of Iron Tailing Powder Fineness and Dosage on Mortar Fluidity}

Mortar fluidity results of different samples are shown in fig. 2 which indicates that iron tailing powders with $3 \%$ to $50 \%$ can improve mortar fluidity, and with the increase of iron tailing powder, fluidity increases, especially when dosage of OP is $8 \%$ and that of GP is $20 \%$ fluidity is $213 \mathrm{~mm}$ and $208 \mathrm{~mm}$ respectively which is maximum and is about $29 \%$ and $26 \%$ higher than that of contrast samples. Comparing the impact of two iron tailing powders on fluidity, it is found that GP can increase fluidity much greater.

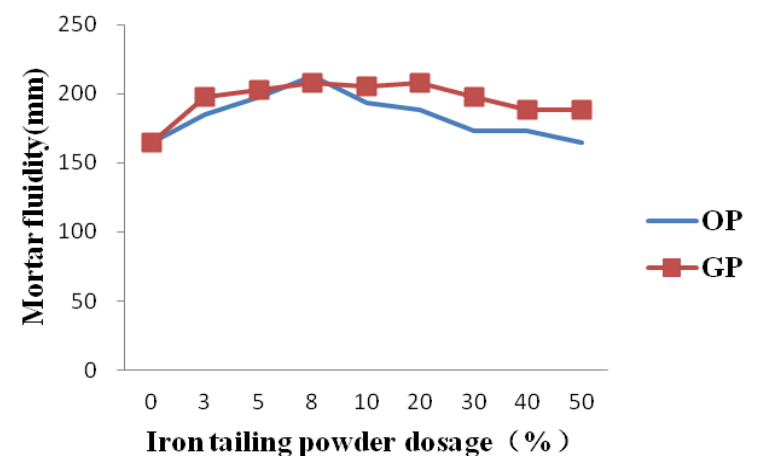

Fig. 2 Effect of iron tailing powder fineness and dosage on fluidity 
Bying filling the space between the cement particles, iron tailing powder can reduces amount of water and improve fluidity, and GP can better able to fill the gaps, so can increase fluidity more.

In a word, iron tailing powder can greatly improve the fluidity and shows a certain water reducing effect.

\section{Effect of Iron Tailing Powder Fineness and Dosage on Strength}

Fig. 3 show the effect of iron tailing powder on mortar strength. When the dosage of OP is less than $8 \%$ the compressive strength for all ages are greater than that of contrast sample, and when dosage is more than $8 \%$ the compressive strengths significantly reduce. For GP, dosage is less than $30 \%$ the compressive strength is greater than that of contrcst sample. With the same dosage, GP can improve strength more.

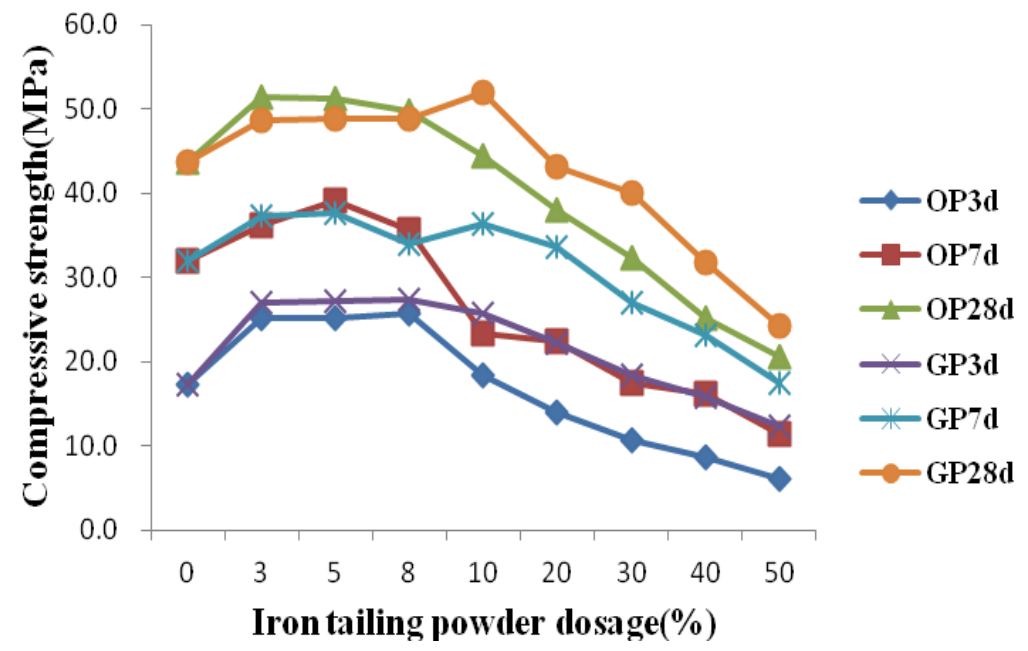

Fig.3 Effect of iron tailing powder fineness and dosage on compressive strength

E.Ringot etc thought that the most important thing to improve the crack resistance of concrete was to reduce its brittleness [8]. Brittleness coefficient is generally defined as the ratio of compressive strength and tensile strength (or flexural strength, splitting tensile strength) of concrete, the smaller the ratio, the smaller the brittleness, the greater the toughness, the better the crack resistance of concrete [9]. The effect of iron tailing powder dosage on brittleness coefficient (compressive to flexural strength) is shown in Fig. 4.

When the dosage of iron tailing powder is more than $20 \%$, brittleness coefficient is lower than the contrast sample, which shows that a certain amount of iron tailing powder can effectively reduce the brittleness coefficient of cement mortar, and improve crack resistance.

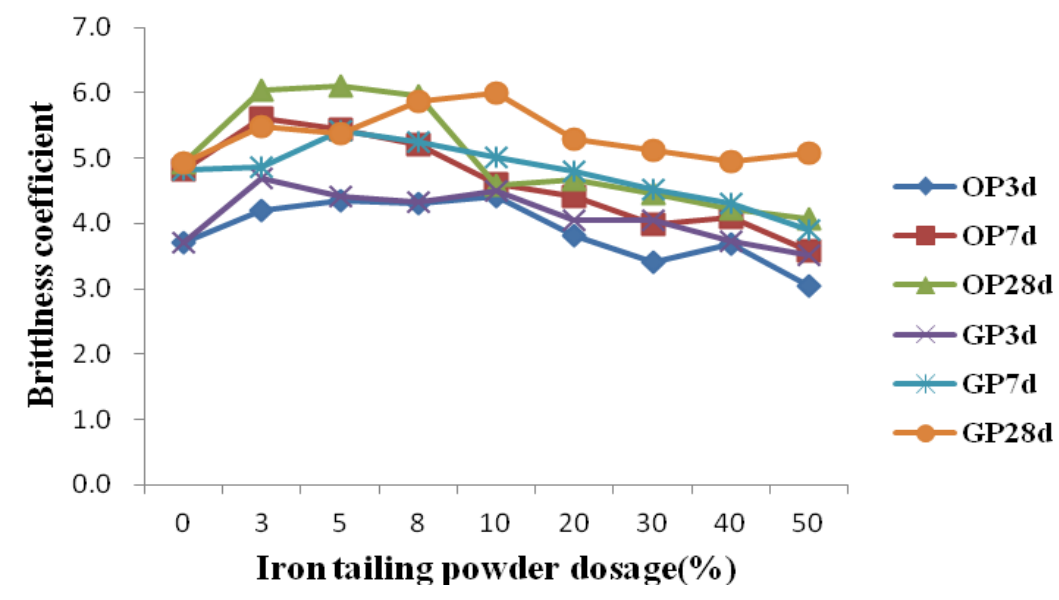

Fig.4 Effect of iron tailing powder on brittlness coefficient 


\section{Activity Analysis of Iron Tailing Powder}

Professor PU Xincheng[10] proposed the activity index evaluation method for mineral material by which can analyse the activity of mineral materials by calculating the specific strength, specific strength coefficient and active index (also known as contribution rate of activity). Specific strength of contrast sample $\left(\mathrm{R}_{\mathrm{sc}}\right)$ and specific strength of sample with mineral admixtrue refer with eguation 1 and 2 , and specific strength coefficient $(\mathrm{K})$ refer with equation 3 , and contribution rate of activity $\left(\mathrm{P}_{\mathrm{a}}\right)$ refer with equztion 4.

$$
\mathrm{R}_{\mathrm{gc}}=\frac{\mathrm{R}_{\mathrm{c}}}{100}
$$

$\mathrm{R}_{\mathrm{c}}$ means strength of contrast concrete or mortar, $\mathrm{MPa}$;

$$
\mathrm{R}_{\mathrm{ga}}=\frac{\mathrm{R}_{\mathrm{a}}}{q_{\mathrm{o}}}
$$

$\mathrm{R}_{\mathrm{a}}$ means strength of concrete or mortar with mineral admixtures , $\mathrm{MPa}$;

$q_{0}$ means cement mass fraction in sample with mineral admixtures , $\%$

$$
\begin{aligned}
& \mathrm{K}=\frac{\mathrm{R}_{\mathrm{ga}}}{\mathrm{R}_{\mathrm{gc}}} \\
& \mathrm{P}_{\mathrm{a}}=\frac{\mathrm{R}_{\mathrm{gp}}}{\mathrm{R}_{\mathrm{ga}}} \times 100 \% \\
& \mathrm{R}_{\mathrm{gp}}=\mathrm{R}_{\mathrm{ga}}-\mathrm{R}_{\mathrm{gc}}, \mathrm{MPa} .
\end{aligned}
$$

Fig. 6 to Fig.8 show specific strength, specific strength coefficient and contribution rate of activity of iron tailing powder.

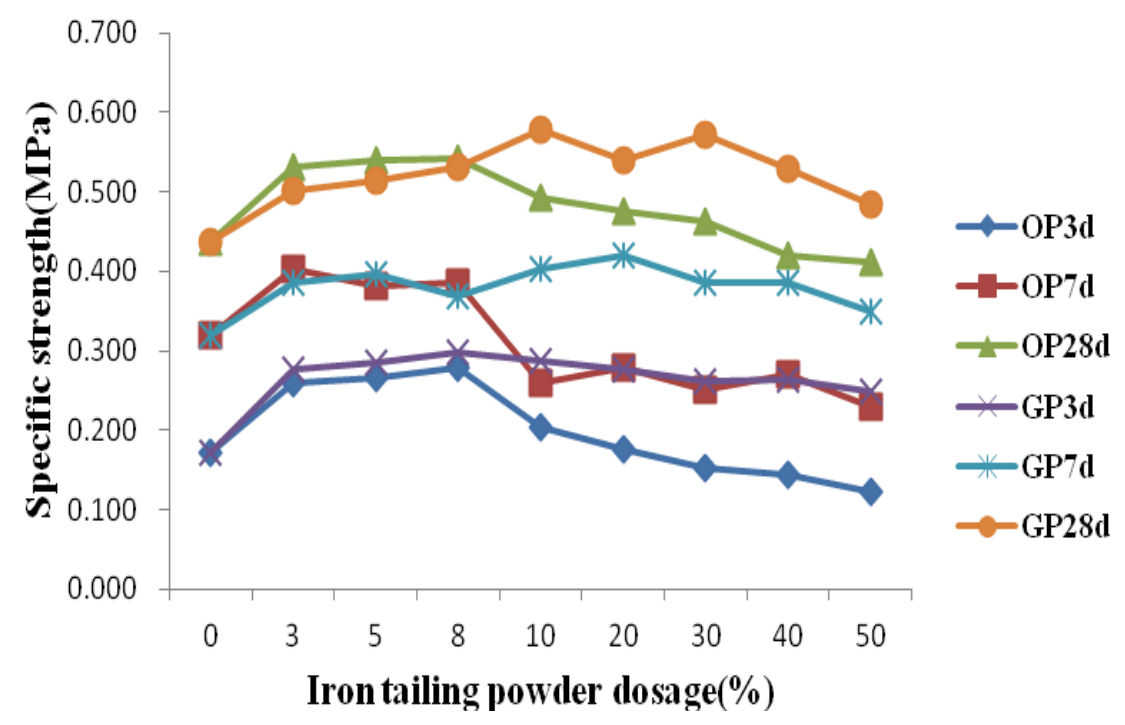

Fig.6 Effect of iron tailing powder on specific strength

Comparing Fig. 3 with Fig.6, it finds that when dosage of iron tailing powder is low, the curves of compressive strength and specific strength are similar, but when dosage is high, specific strength curve is more gentle, especially when mixed with GP, which can reflect the effect extent of iron tailing powder on strength. 
Fig.7 shows that the impact of iron tailing powder dosage on specific strength coefficient is consistent with specific strength. When the sodage of OP is within $8 \%, \mathrm{~K}$ is more than 1 , and when the dosage is upto $10 \%, \mathrm{~K}$ is less than 1 and decreases with the increase of iron tailing powder. For GP, corresponding $\mathrm{K}$ is greater than 1 with all dosages.

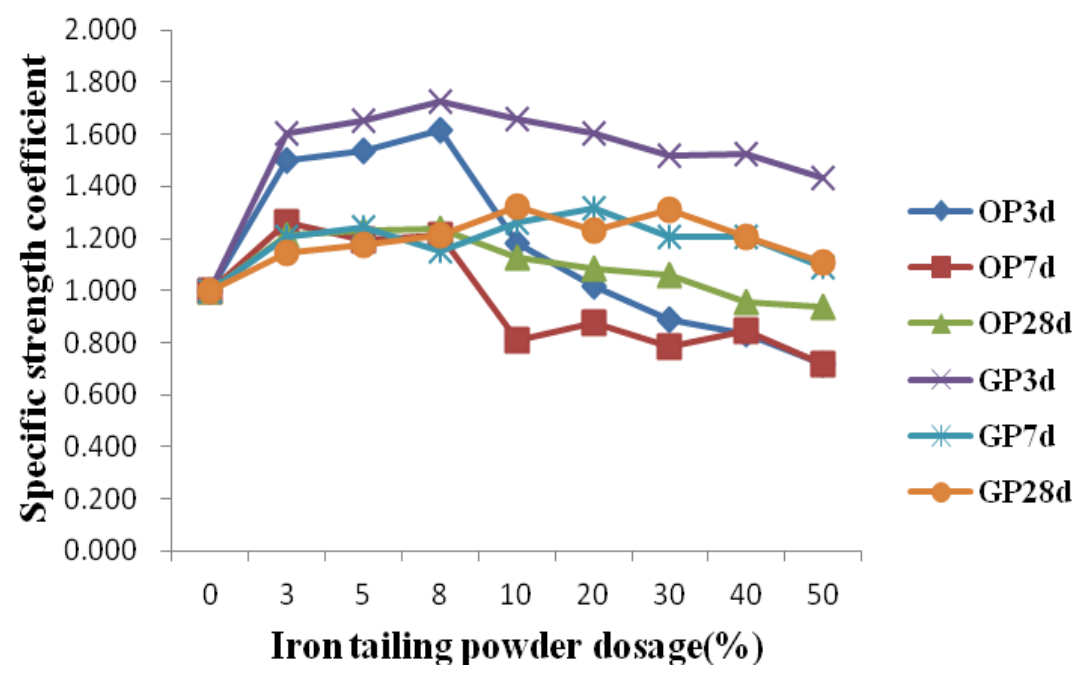

Fig.7 Effect of iron tailing powder on specific strength coefficient

It can be seen in Figure 8 that when the dosage of OP is low, such as $8 \%$ of 7 days and $30 \%$ of 28 days, $\mathrm{P}_{\mathrm{a}}$ is greater than 0 , but when the dosage is too great, $\mathrm{P}_{\mathrm{a}}$ is less than 0 , which indicates that when the dosage of OP at a low value, OP can has a certain strength contribution. When the dosage of GP reaches to $50 \%$, its strength contribution rate is greater than 0 , which shows that when the dosage of GP is within $50 \%$, all have certain strength contribution.

In a word, the three parameters, they are $\mathrm{R}_{\mathrm{sa}}, \mathrm{K}$ and $\mathrm{P}_{\mathrm{a}}$, can objectively reflect the influence of iron tailing powder on cement mortar strength.

Due to the activity of iron tailing powder itself is very low, its contribution to the cement mortar strength mainly depends on physical filling effect. Because the fineness of OP and cement are close, the particles of OP can only fill larger gaps between the cement particles, the dosage is low. Tthe particles of GP are very small, which can fill smaller gaps between the cement particles and will better perform its "filling effect".

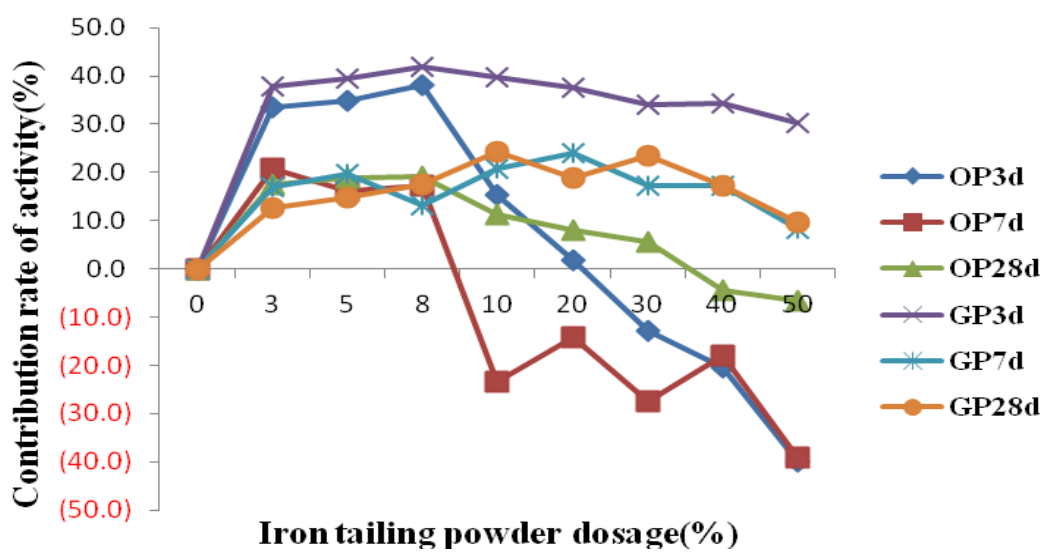

Fig. 8 Effect of iron tailing powder on contribution rate of activity

\section{Conclusion}

Iron tailing powder can improve the fluidity of cement mortar, and has water-reducing effect which is better with fineness increasing. 
When dosages of OP is less than $10 \%$ and that of GP is less than $30 \%$, iron tailing powders can improve strength, and at the same dosage, GP can increase strength more.

When dosage of iron tailing powder is less than $20 \%$, it can improve crack resistance.

When dosage of OP is within $20 \%$ and that of GP is within 50\%, iron tailing powders can improve specific strength and specific strength coefficient. When dosage of OP is less than $20 \%$ and that of GP is less than $50 \%$, the contribution rate of activity is greater than 0 , which shows that iron tailing powder has a certain role to promote the development of strength.

The contribution of iron tailing powder to mortar strength mainly depends on physical filling effect. The effect of iron tailing powder on the contribution rate of activity mainly depends on its fineness.

\section{References}

[1]LIU yongguang, Development of recycling comprehensive utilization on iron tailing, J. Modern Mining. 2(2010) 28-30.

[2]XIAO liguang, Status of comprehensive utilization of iron tailing at home and abroad, J. Journal of JiLin Institute Architectural and Civil. 27(4)(2001) 22-23.

[3]KANG huirong, CHEN jianbing, KANG suiping, Experimental study on calcined cement using iron tailing instead of sulfate slag, J . Cement, 1(2004) 23-24.

[4]HUANG shiwei, LI yanyan, CHENG lin, Preparation of not-fired and not-steamed brick using iron tailing in Meishan, J. Metal Mine. 4(2007) 81-84.

[5]XIE hongbo, LIN kehui, LI xiangtao, Experimental study on production of autoclaved aerated concrete using tailing sand, J. China Concrete and Cement Products. 4(2010) 69-71.

[6]ZHENG yongchao, NI wen, ZHANG xufang, Experimental study on preparation of fine aggregate concrete using fine iron tailing, J. Metal Mine. 12(2009) 151-153.

[7]SONG yuzeng, LIU shuting, CAI jiwei, Workability and strength property of iron tailing sand concrete, J. Construction Quality. 23(2001) 62-65.

[8]E.Ringot, A.Bascoul, About the Analysis of Microcraking in Concrete, J. Cement and Concrete Composites. 23(2001) 261-266.

[9]LIU shuhua, FANG kunhe, Anti-cracking property evalution on rolled compacted concrete, J. Water Power. 9(2007) 20-22.

[10]PU xincheng, Super high strength high performance concrete Principles. Preparation. Structure. Performance. Application, Chongqin University Press, 2004. 